\title{
Changes in Physiological and Psychological Conditions of Humans to Color Stimuli of Plants
}

\author{
Hye Sook Jang, Gyung Mee Gim, Sun Jin Jeong, and Jae Soon Kim* \\ National Institute of Horticultural \& Herbal Science, RDA, Wanju-gun 55365, Korea
}

\begin{abstract}
This study investigates the color stimuli of two varieties of foliage plants by extracting electroencephalogram, electrocardiogram and physiology activity data from 30 participants in their 50s or older. Changes in the physiological activity of subjects against six color stimuli were examined. The stimulus to real green plants 'Silver Queen' was set as the control group, and was compared with other groups including the stimulus to real 'Angel' plants and four stimuli to artificial colors (two color images and color schemes of the same green and red plants). Compared to the five groups, the relative theta power spectrum (RT) and the ratio of alpha to high beta (RAHB) increased in the subjects exposed to real green plants. This result demonstrates that the green plant ('Silver Queen') increases the stability, relaxation, and internal concentration of subjects in a proper state of awakening. The result of this experiment showed a statistically significant difference in the level of RT when subjects were exposed to the groups of real green and red plants. This finding indicates that the green plant increases internal concentration more than the red plant. RT and the relative low beta power spectrum (RLB) in the groups of natural colors were higher than the groups of artificial colors when subjects focused their mind on the two types of real plants. However, the level of relative mid beta power spectrum (RMB), ratio of SMR to theta (RST), ratio of mid beta to theta (RMT), relative high beta power spectrum (RHB), and spectral edge frequency $95 \%$ were higher when subjects were exposed to the photos and colors scheme of plants than when they were exposed to real plants. The subjects experienced more "comfortable" emotions when they were looking at plants with green colors. Overall, it is recommended to use the natural colors of real plants in places where which stability and relaxation are required. On the contrary, the artificial colors of plants such as their photos and color schemes are useful in places where a high level of concentration is required in a short period of time.
\end{abstract}

Keywords: ECG, EEG, frontal lobe, occipital lobe, parietal lobe, psychology, temporal lobe

\section{Introduction}

In image recognition, color among several elements of the visual environment is closely related to emotions (Valdez and Mehrabian, 1994). Colors affect humans in various ways, and have long been used in therapy. Among them, green is a color that represents nature and is known to give a sense of relaxation and stability (Kwon and Park, 2004). It was reported that people who travel around natural environments show a significantly lower level of stress and strain that might be felt

This study was supported by the 2019 Horticultural and Herbal Science Program of the National Institute of Horticultural and Herbal Science of the Rural Development Administration (PJ01137604).

Received: March 5, 2019, Revised: March 21, 2019, Accepted: April 15, 2019

First author: Hye Sook Jang, E-mail: jhs915@korea.kr, (1) https://orcid.org/0000-0003-3011-8694

*Corresponding author: Jae Soon Kim, E-mail: kimjs81@korea.kr, (1) https://orcid.org/0000-0002-6529-3225 
like a crisis in life than those who do not, which demonstrates that natural environments or plants have a positive impact on the psychological and emotional state of humans (Shibata and Suzuki, 2002; Wells and Evans, 2003; Ottosson and Grahn, 2008). Maintaining an appropriate level of greenness in consideration of the colors, texture and shape of plants for the mental stability of humans have various effects including psychological effects (Yoo, 1999). In fact, subjects showed a lower level of strain and anxiety when they saw nature and sceneries of indoor plants through windows than urban landscapes, and they showed a high level of strain and anxiety when they could see neither window nor plants (Chang and Chen, 2005). In addition, looking at natural colors of real green plants had a more positive impact on the brainwaves and psychophysiology of people than looking at other artificial colors on newspaper or monitors (Lee and Son, 1999; Son et al., 1999).

Recently, electroencephalogram (EEG) or electrocardiogram (ECG) started to be used to obtain more objective data about the effects of the colors of flowers or leaves on changes in the psychological state of humans, but they have not been used often. EEG is a monitoring method to measure the electrical activity of the cerebral cortex by recording and observing the activity of the brain (Berger, 1929), and has been used as an indicator of the psychophysiological conditions of humans. The frontal lobe is the part of the brain that controls intellectual/conceptual plans, personality, speech production, etc., while the temporal lobes control auditory stimuli, memory, language, etc. The parietal lobes are involved in verbal and visual/spatial processes, and the occipital lobes play an important role in visual and cognitive functions (Korea Neuropsychiatric Association, 1997; Simonov, 1997).

This study analyzed the correlation of six color stimuli with the results of semantic differential (SD) survey and EEG in order to examine the correlation between emotions and body reactions to plants or artificial colors based on changes in EEG to the environments with natural colors and artificial colors, focusing on the visual emotional elements of humans among various functions of plants.

\section{Research Methods}

\section{Selection of subjects}

To examine the effects of the color stimuli of foliage plants on changes in the electroencephalogram (EEG), electrocardiogram (ECG) and psychological state of middle-aged people in their 50s, a total of 30 people (10 males, 20 females) aged 55.2 years $( \pm 3.90)$ on average were tested in this study. Since most pre-seniors in their 50 s or older have taken drugs for a long time due to chronic diseases, those who have chronic diseases such as high blood pressure and diabetes or have taken drugs for a long time were excluded from subjects. The selection criteria used in brain research in general were also adopted (Son et al., 1998, 1999; Lee, 2009; Jang et al., 2014), and subjects were selected among those who voluntarily signed a consent form for participation. The selected subjects were instructed not to drink for 2 days prior to this test in principle, and were banned from drinking any beverage that stimulates the brain from 2 hours before this test. Subjects were fully informed of the purpose and procedures of this test in advance to ensure they understand and cooperate with this test.

\section{Laboratory environment}

Electroencephalogram (EEG) and electrocardiogram (ECG) were measured and a semantic differential (SD) survey was conducted in a room at $\mathrm{K}$ research center between 10 a.m. to 4 p.m. (Figure 1). The room was surrounded by light gray walls (length $4.5 \mathrm{~m} \times$ width $2.7 \mathrm{~m} \times$ height $2.6 \mathrm{~m}$ ). To prevent any impact of extraneous light on the psychological state of 

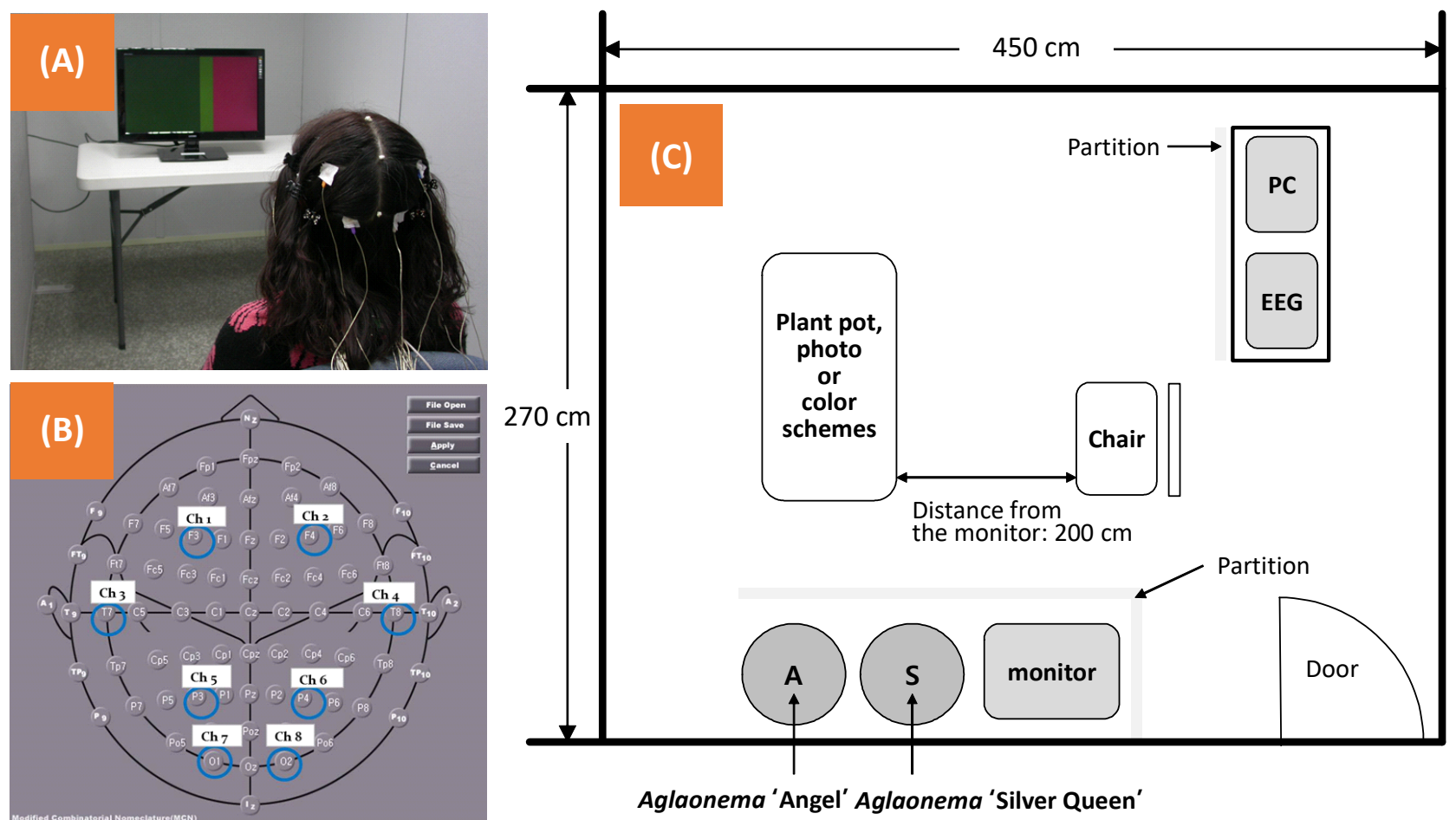

Figure 1. Experimental set-up: (A) data collection for a subject, (B) positions of eight electrodes and materials used for electroencephalography measurements from the top view of the scalp, (C) room arrangement for experiment.

subjects, extraneous light was blocked and the fluorescent lights on the ceiling were turned on. The intensity of illumination at the height of a table from the floor was maintained at 400 10 lux (UT383 Mini Light Meters, Japan) on average. Temperature and humidity were maintained at $25 \pm 0.5^{\circ} \mathrm{C}$ and $70 \pm 10 \%$ respectively.

\section{Test plants and methods}

Indoor foliage plants including two Aglaonemas species ('Silver Queen' and 'Angel') were used in this test, and a total of six groups of stimuli were set up as follows: real plants (natural colors); color images of the plants (artificial colors); and color schemes of the leaves of the plants. The EEG and ECG of subjects were measured and an adjective check list test was conducted for each group (Figures 1 and 2). The natural color groups of real plants included Aglaonema 'Silver Queen' plants with green leaves and Aglaonema 'Angel' plants with red leaves. The artificial color groups used the photos of the same plants, and the color schemes of the same plants were produced based on the color ratio of the leaves of the real plants. The natural color group of Aglaonema 'Silver Queen' plants with green leaves was used as the control group. The six groups were divided as follows: the natural color of real 'Silver Queen' plants with green leaves (AV group); the natural color of real 'Angel' plants with red leaves (BV group); the artificial colors of the photos of the same plants (AP and BP respectively); and the color schemes of the same plants produced based on the color ratio of their leaves (AC and $\mathrm{BC}$ respectively). The $\mathrm{AV}$ group was used as the control group and compared it with other groups. The height of one real plant planted in a pot (diameter $20 \mathrm{~cm}$, height $25 \mathrm{~cm}$ ) was $45( \pm 5) \mathrm{cm}$, and five pots were grouped together, and the photos of the real plants were taken and used in the AP and BP groups respectively. The color schemes of the same plants were also produced based on the color ratio of the leaves of 'Silver Queen' and 'Angel' plants and were used in the $\mathrm{AC}$ and $\mathrm{BC}$ groups respectively. To test the reliability of the color schemes, the color schemes of five leaves taken from 
each of the five plants of each variety were produced. The produced color schemes were presented to three color specialists, and those selected by them were used in this test. The two groups of the photos of real plants, and the two color scheme groups produced based on the color ratio of the leaves of real plants were presented to subjects using a 24-inch monitor. While they looked at each of the six groups, their EEG and ECG were measured and a SD survey was conducted.

Subjects were instructed to lean back in a chair located approximately $2 \mathrm{~m}$ away from the test object in the most comfortable position, while their EEG and ECG were measured (Kim, 1998; Jang et al., 2014). The EEG and ECG monitors were placed $30 \mathrm{~cm}$ behind the subjects. When they entered the test room, they were informed of the overall process of this test and signed a consent form for participation. While a total of 12 electrodes were attached to the subjects, they were allowed to familiarize themselves with the new environment. Eight channels of disc-type electrodes coated with gold were applied with an EEG glue (Elefix z-401ce, Nihon Kohden) and were attached to the scalp of subjects. A reference electrode (A1) and a ground electrode (A2) were also places. A disposable ECG electrode was attached under the left breast and above the right breast respectively (Table 1). To control extraneous noises, subjects were instructed to wear
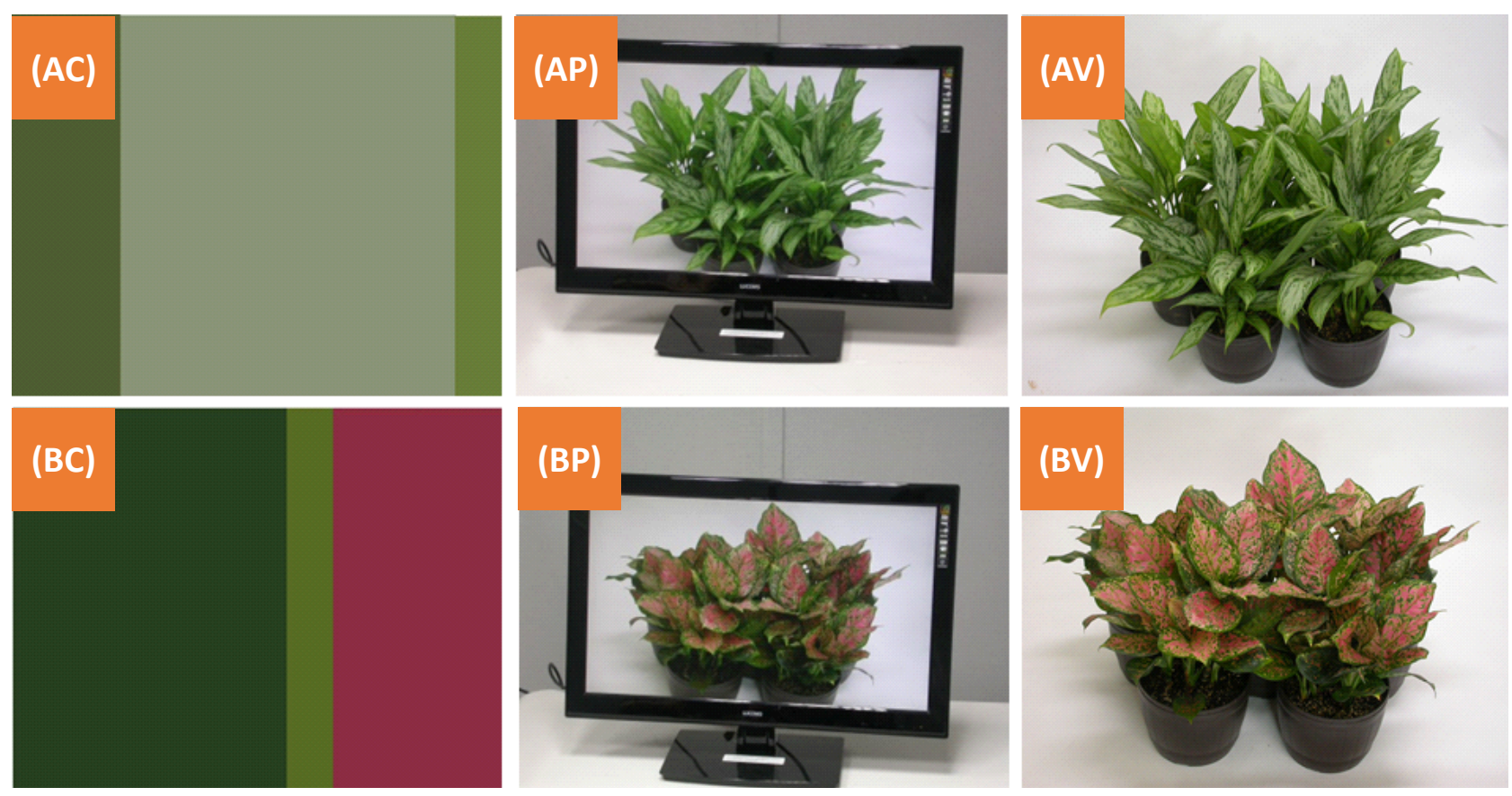

Figure 2. Stimuli used in experimental set-up: (AC) color scheme of Aglaonema 'Silver Queen,' (AP) color image of $A$. 'Silver Queen,' (AV) real $A$. 'Silver Queen' plants in pots, (BC) color scheme of $A$. 'Angel,' (BP) color image of $A$. 'Angel,' (BV) real $A$. 'Angel' plants in pots.

Table 1. Experimental procedure for EEG and ECG visual stimuli

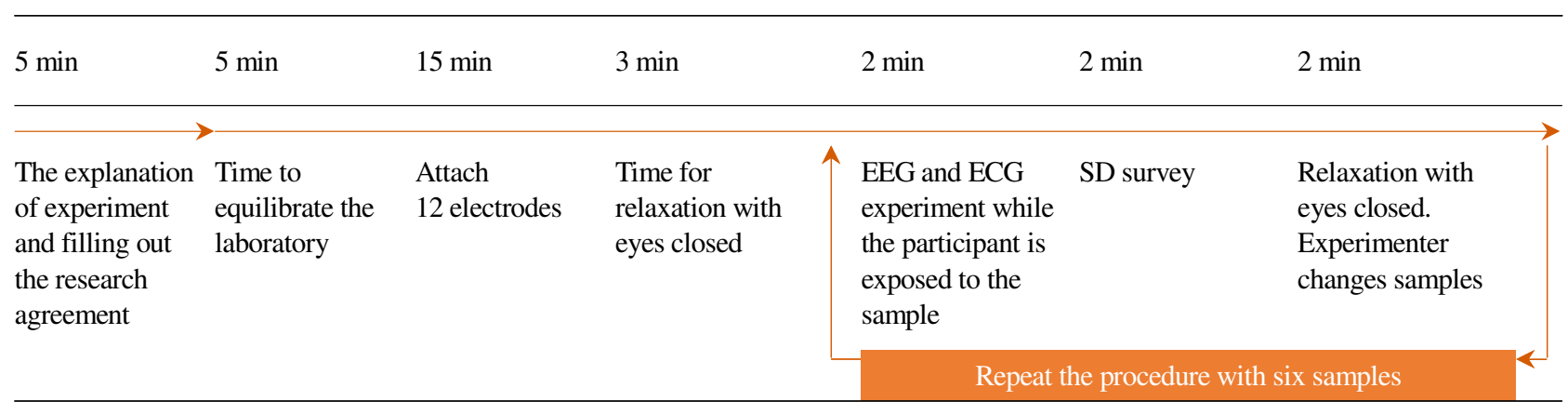


disposable earplugs. Before measuring EEG and ECG, they were instructed to close their eyes and relax for 3 minutes while the first test plant was placed. To ensure subjects can see real plants in a comfortable position, they were placed on the floor considering their height. The computer monitor used to show the images and color schemes of the same plants was placed on a table $(120 \times 45 \times 70 \mathrm{~cm})$. During the test, one plant or image at a time was shown to subjects, and a partition was placed to ensure the subjects could not see other objects in advance. The EEG of subjects was measured for 2 minutes 10 seconds for each group, and a SD survey was performed for 2 minutes. After completing the SD survey, they were instructed to close their eyes for 2 minutes and their EEG and ECG were measured after that. The same process was repeated for each of the six groups. Plants and the computer monitor used in this test were quickly replaced while the subjects closed their eyes and relaxed for 2 minutes between groups. The order of groups was varied for each subject. Since subjects saw one group at a time, it took a total of 65 minutes to conduct this test for an individual subject.

\section{EEG measurement and analysis method}

The computerized EEG (brain mapping) of subjects was measured using BIOS-S9 (Bio-Brain Inc., Daejeon, Korea). Electrodes used to measure EEG were located, according to the International 10-20 system (Jasper, 1958), at 8 points as follows: F3, F4, T3, T4, P3, P4, O1 and O2 (8 channels), and EEG was measured using monopolar derivation (Figure 1). The placement site of each electrode is named depending on the area of the brain (left or right, front or rear). Each letter identifies the area of the brain as follows: F, frontal lobes; T, temporal lobes; P, parietal lobes; and O, occipital lobes. Odd numbers mean the left hemisphere, and the even numbers mean the right hemisphere. EEG was measured for 130 seconds, and the analog filter passing band width was $0.5-50 \mathrm{~Hz}$. The sampling frequency was $250 \mathrm{~Hz}$, and the bit resolution was 24 bit. The most frequently used quantitative EEG analysis technology is the discrete fourier transformation (DFT). The DFT converts time series EEG signals into spectral sequences within a frequency domain. In the 1960s, the fast fourier transformation (FFT) algorithm was developed to increase the speed of computing. To analyze physiological signals, this study obtained the power spectrum of each frequency band from the measured EEG and ECG data using the FFT algorithm, and their relative power was compared in order to minimize differences between individuals. The measured EEG and ECG data were analyzed using BioScan 1.0 software (BioBrain Inc., Daejeon, Korea). Noises observed in the measured EEG are mostly caused by heart beats or movements of the eyes and eyeballs, and they occur in the frequency band of $4 \mathrm{~Hz}$ or lower. This study eliminated the frequency band of $4 \mathrm{~Hz}$ or lower to minimize the impact of the noises. In addition, at each electrode, the mean value of the power spectrum was obtained, and brain maps were produced based on them. Brain maps showed changes in the power spectrum values, and high and low values were colored in red and blue respectively.

\section{Semantic differential (SD) measurement}

Semantic differential (SD) surveys are widely used to evaluate elements, such as landscapes that are difficult to quantify, based on the subjective taste of individuals in relation with representative emotional factors obtained through emotional adjectives or factor analysis (Jo, 2009; Park, 2010; Kim, 2012). The questionnaire of emotional words used in this study contain image adjectives used in an earlier study to evaluate landscapes (Im, 2009), and 14 pairs of emotional words related to plants (Choi et al., 1997; Kim, 2009; Jang et al., 2014), and a Likert's 5-point scale (1 point: left, 5 points: right) was used. The SD scale suggested by Charles E. Osgood, an American psychologist (Osgood et al., 1957) was used in this study. The SD scale is widely used to evaluate emotions or landscapes (Park, 2010; Kim, 2012). Chronbach's reliability value of the emotional words was $\alpha=.934$. 


\section{Statistical analysis}

Statistical analysis was conducted using IBM SPSS ver. 21.0. The reliability of measuring tools was analyzed by calculating Cronbach's $\alpha$. The relative power of EEG and ECG and emotional words were analyzed through repeated measures ANOVA and paired t-test, and the correlation between emotional words and EEG was analyzed using Pearson's correlation analysis.

\section{Results and Discussion}

\section{Changes in EEG caused by the color stimuli of two types of foliage plants}

The group of real 'Silver Queen' plants and that of the color scheme of 'Silver Queen' were compared, and the group of real 'Silver Queen' plants showed a significantly higher level of relative theta power spectrum (RT) in the occipital lobe on the left hemisphere, and a significantly higher ratio of alpha to high beta (RAHB) in the parietal lobe on the left hemisphere and the occipital lobe on the right hemisphere than the group of the color scheme of 'Silver Queen' (Tables 2 and 4; Figure 3). The group of real 'Silver Queen' plants showed a significantly lower level of relative mid beta power spectrum (RMB) in the occipital lobes (O1, O2), a significantly lower ratio of SMR to theta (RST) in the occipital lobe on the right hemisphere, and a significantly lower ratio of mid beta to theta (RMT) in the parietal lobe on the left hemisphere and in the occipital lobes $(\mathrm{O} 1, \mathrm{O} 2)$ than the group of the color scheme of 'Silver Queen' plants $(p<.05)$ (Tables 3 and 4; Figure 3). While looking at real 'Silver Queen' plants, the level of RT and RAHB that indicates relaxation and pleasantness increased in the parietal lobes and the occipital lobes that control visual and spatial functions (Jin, 2011), which shows that internal concentration and the level of stability and relaxation increased more while looking at the natural colors of real plants than while looking at the artificial colors of the color scheme of 'Silver Queen' plants. These results are similar to those of earlier studies (Hutchsion, 1996; Schacter, 1977) that theta waves increased while people focused on tasks that they were aware of or perceived and did the tasks in an efficient way, and that theta waves increased more clearly when people concentrated their mind on their inner side than other waves did. These results can be interpreted that people tend to concentrate on their inner side when real plants are in front of them, not when photos of plants or images of color schemes are displayed on a monitor screen. In addition, the level of theta waves in the parietal lobes and the occipital lobes that controls visual functions was lower when subjects looked at real 'Silver Queen' plants than when subjects looked at the color scheme of 'Silver Queen' plants, which indicates that the level of awakening and strain against visual stimuli was lower when looking at real 'Silver Queen' plants than when looking at the color scheme of 'Silver Queen' plants. At the same time, relative high-beta power spectrum (RHB) and spectral edge frequency 95\% (SEF95) in the group of the color scheme of 'Silver Queen' plants were higher in the occipital lobe on the right hemisphere than the group of real 'Silver Queen' plants, which indicates that the visual stimuli of the color scheme of 'Silver Queen' plants increased concentration more than real 'Silver Queen' plants, but active activities of the brain caused strain and stress.

The group of real 'Silver Queen' plants and that of the photos of real 'Silver Queen' plants were compared, and the group of real 'Silver Queen' plants showed a significantly higher level of relative theta power spectrum (RT) in the temporal lobe on the left hemisphere, the parietal lobe and the occipital lobe, and a significantly higher relative low beta power spectrum (RLB) in the frontal lobe on the left hemisphere that plays a central role in the functions of the brain and controls thinking ability and the overall brain functions (Tables 2 and 4; Figure 3). In addition, the groups of real 'Silver Queen' plants showed a significantly lower relative mid beta power spectrum (RMB) in the temporal lobe on the left hemisphere and the occipital lobes $(\mathrm{O} 1, \mathrm{O} 2)$ and a significantly lower ratio of mid beta to theta (RMT) in the occipital lobe on the right 
hemisphere than the group of the photos of real 'Silver Queen' plants ( $p<.05)$ (Tables 3 and 4; Figure 3). The level of RT in the group of real 'Silver Queen' plants was higher in the temporal lobe, the parietal lobe and the occipital lobes than the group of the photos of real 'Silver Queen' plants, which shows that internal concentration increased more while looking at real 'Silver Queen' plants than while looking at their photos. In addition, the level of RLB in the frontal lobe on the left hemisphere that controls advanced cognitive, emotional and mental functions (Jin, 2011) in the group of real 'Silver Queen' plants was higher than the group of the photos of real 'Silver Queen' plants, which can be interpreted that looking at real 'Silver Queen' plants is more effective in improving attention in the state of awakening than looking at their photos. However, the group of real 'Silver Queen' plants showed a lower level of RMB and RMT that indicate the level of attention with strain in the parietal lobe and the occipital lobe than the group of the photos of real 'Silver Queen' plants, which can be interpreted that the natural colors of real 'Silver Queen' plants showed a lower level of strain caused by visual stimuli, but a higher level of relaxation than the artificial colors of the photos of real 'Silver Queen' plants. At the same time, the group of the photos of real 'Silver Queen' plants showed a higher level of relative high beta power spectrum (RHB) in the occipital lobe on the right hemisphere than the group of real 'Silver Queen' plants. The result can be interpreted that the photos of 'Silver Queen' plants showed a higher level of attention but their visual stimuli also caused a high level of strain and stress.

The group of real 'Silver Queen' plants with green colors and that of the color scheme of 'Angel' plants with red colors were compared, and the group of real 'Silver Queen' plants showed a significantly higher level of relative theta power spectrum (RT) in the temporal lobe on the left hemisphere, the parietal lobe and the occipital lobe, and a significantly higher ratio of alpha to high beta (RAHB) in the frontal lobe on the right hemisphere than the group of the color scheme of 'Angel' plants (Tables 2 and 4; Figure 3). However, the group of real 'Silver Queen' plants showed a significantly lower relative low beta power spectrum (RLB) in the temporal lobe on the left hemisphere, the parietal lobe and the occipital lobe, a significantly lower level of relative mid beta power spectrum (RMB) in the occipital lobes (O1, O2), and a significantly lower ratio of mid beta to theta (RMT) in the parietal lobes (P1, P2) and the occipital lobe than the group of the color scheme of 'Angel' plants (Tables 2-4; Figure 3). The group of real 'Silver Queen' plants showed a higher level of RT and RAHB than the group of the color scheme of ‘Angel' plants, which can be interpreted that real 'Silver Queen' plants were effective in decreasing the level of awakening and strain, and effective for relaxation. In addition, the group of real 'Silver Queen' plants showed a lower level of RLB, RMB, RST and RMT than the group of the color scheme of 'Angle' plants, which indicates that real 'Silver Queen' plants were effective for relaxation, but not effective for strain and attention. However, the group of real 'Silver Queen' plants showed a significantly higher level of relative high-beta power spectrum (RHB) and spectral edge frequency 95\% (SEF95), an indicator of brain activity, in the occipital lobe than the group of the color scheme 'Angel' plants (Tables 2-4; Figure 4), which indicates that the visual stimuli of the color scheme of 'Angel' plants showed a higher level of attention under a high level of strain and stress than real 'Silver Queen' plants $(p$ <.05). These results were similar to those of earlier studies. Lee and Son (1999) reported that the color of green, photos of plants, and real plants gave the highest level of happiness, and Kim and Lee (2009) found that spaces colored in yellow and blue can be viewed as a spatial element that gives pleasure. Green colors showed a higher level of theta waves that are increased by inducing emotions such as pleasure, displeasure and joy (Kim, 2000) than red colors, which can be interpreted that the visual stimuli of green colors have a more positive impact on pleasant emotions than strong red colors.

The group of real 'Silver Queen' plants and that of the photos of real 'Angel' plants were compared, and the group of real 'Silver Queen' plants showed a significantly higher level of relative theta power spectrum (RT) and ratio of alpha to high beta (RAHB) in the occipital lobe on the right hemisphere than the group of the photos of 'Angel' plants (Tables 2 and 4; Figure 3). The group of real 'Silver Queen' plants showed a significantly lower level of relative mid beta power 
Table 2. Overall comparison of electroencephalography results for subjects when viewing color scheme of Aglaonema 'Silver Queen' (AC), color image of $A$. 'Silver Queen' (AP), real $A$. 'Silver Queen' plants (AV), color scheme of $A$. 'Angel' (BC), color image of $A$. 'Angel' (BP), and real $A$. 'Angel' plants (BV)

\begin{tabular}{|c|c|c|c|c|c|c|c|c|c|}
\hline $\mathrm{EEG}^{\mathrm{z}}$ & Color & $F 3^{y}$ & F4 & $\mathrm{T} 3$ & $\mathrm{~T} 4$ & P3 & P4 & $\mathrm{O} 1$ & $\mathrm{O} 2$ \\
\hline \multirow{6}{*}{ RT } & $\mathrm{AC}$ & $0.410 \pm 0.13$ & $0.422 \pm 0.14$ & $0.291 \pm 0.13$ & $0.303 \pm 0.14$ & $0.286 \pm 0.12$ & $0.302 \pm 0.12$ & $0.249 \pm 0.12$ & $0.264 \pm 0.12$ \\
\hline & $\mathrm{AP}$ & $0.400 \pm 0.14$ & $0.417 \pm 0.16$ & $0.265 \pm 0.18$ & $0.301 \pm 0.13$ & $0.267 \pm 0.11$ & $0.293 \pm 0.12$ & $0.259 \pm 0.12$ & $0.293 \pm 0.12$ \\
\hline & AV & $0.387 \pm 0.15$ & $0.397 \pm 0.15$ & $0.324 \pm 0.13$ & $0.305 \pm 0.17$ & $0.319 \pm 0.15$ & $0.320 \pm 0.15$ & $0.316 \pm 0.12$ & $0.363 \pm 0.15$ \\
\hline & $\mathrm{BC}$ & $0.376 \pm 0.12$ & $0.388 \pm 0.12$ & $0.262 \pm 0.09$ & $0.262 \pm 0.11$ & $0.267 \pm 0.09$ & $0.272 \pm 0.10$ & $0.233 \pm 0.10$ & $0.241 \pm 0.11$ \\
\hline & BP & $0.416 \pm 0.15$ & $0.427 \pm 0.16$ & $0.292 \pm 0.15$ & $0.308 \pm 0.16$ & $0.290 \pm 0.14$ & $0.313 \pm 0.14$ & $0.283 \pm 0.13$ & $0.310 \pm 0.14$ \\
\hline & BV & $0.361 \pm 0.13$ & $0.389 \pm 0.12$ & $0.286 \pm 0.12$ & $0.280 \pm 0.13$ & $0.293 \pm 0.12$ & $0.306 \pm 0.12$ & $0.286 \pm 0.15$ & $0.331 \pm 0.14$ \\
\hline \multirow{6}{*}{ RLB } & $\mathrm{AC}$ & $0.065 \pm 0.02$ & $0.062 \pm 0.02$ & $0.084 \pm 0.03$ & $0.079 \pm 0.02$ & $0.095 \pm 0.03$ & $0.094 \pm 0.03$ & $0.092 \pm 0.03$ & $0.096 \pm 0.04$ \\
\hline & $\mathrm{AP}$ & $0.060 \pm 0.02$ & $0.058 \pm 0.01$ & $0.080 \pm 0.02$ & $0.078 \pm 0.02$ & $0.095 \pm 0.04$ & $0.094 \pm 0.05$ & $0.086 \pm 0.03$ & $0.084 \pm 0.03$ \\
\hline & $\mathrm{AV}$ & $0.067 \pm 0.02$ & $0.061 \pm 0.02$ & $0.082 \pm 0.03$ & $0.075 \pm 0.03$ & $0.094 \pm 0.04$ & $0.088 \pm 0.04$ & $0.081 \pm 0.04$ & $0.084 \pm 0.06$ \\
\hline & $\mathrm{BC}$ & $0.064 \pm 0.02$ & $0.062 \pm 0.02$ & $0.087 \pm 0.02$ & $0.083 \pm 0.03$ & $0.099 \pm 0.03$ & $0.097 \pm 0.05$ & $0.097 \pm 0.04$ & $0.098 \pm 0.04$ \\
\hline & $\mathrm{BP}$ & $0.060 \pm 0.02$ & $0.055 \pm 0.02$ & $0.081 \pm 0.02$ & $0.075 \pm 0.02$ & $0.092 \pm 0.02$ & $0.088 \pm 0.03$ & $0.082 \pm 0.02$ & $0.081 \pm 0.02$ \\
\hline & BV & $0.071 \pm 0.02$ & $0.067 \pm 0.03$ & $0.091 \pm 0.02$ & $0.082 \pm 0.03$ & $0.098 \pm 0.03$ & $0.091 \pm 0.04$ & $0.080 \pm 0.04$ & $0.083 \pm 0.05$ \\
\hline \multirow{6}{*}{ RMB } & $\mathrm{AC}$ & $0.087 \pm 0.02$ & $0.084 \pm 0.02$ & $0.116 \pm 0.03$ & $0.112 \pm 0.03$ & $0.125 \pm 0.04$ & $0.126 \pm 0.05$ & $0.116 \pm 0.03$ & $0.109 \pm 0.02$ \\
\hline & $\mathrm{AP}$ & $0.091 \pm 0.03$ & $0.085 \pm 0.03$ & $0.126 \pm 0.03$ & $0.119 \pm 0.04$ & $0.128 \pm 0.05$ & $0.126 \pm 0.05$ & $0.113 \pm 0.03$ & $0.101 \pm 0.02$ \\
\hline & AV & $0.089 \pm 0.02$ & $0.087 \pm 0.03$ & $0.111 \pm 0.04$ & $0.108 \pm 0.04$ & $0.112 \pm 0.04$ & $0.118 \pm 0.04$ & $0.095 \pm 0.02$ & $0.090 \pm 0.03$ \\
\hline & $\mathrm{BC}$ & $0.095 \pm 0.02$ & $0.095 \pm$ & $0.126 \pm 0.04$ & $0.119 \pm 0.03$ & $0.136 \pm 0.05$ & $0.133 \pm 0.05$ & $0.120 \pm 0.03$ & $0.113 \pm 0.23$ \\
\hline & $\mathrm{BP}$ & $0.084 \pm 0.02$ & $0.079 \pm 0.02$ & $0.114 \pm 0.03$ & $0.109 \pm 0.03$ & $0.124 \pm 0.04$ & $0.118 \pm 0.04$ & $0.104 \pm 0.03$ & $0.093 \pm 0.02$ \\
\hline & $\mathrm{BV}$ & $0.090 \pm 0.03$ & $0.090 \pm 0.03$ & $0.116 \pm 0.03$ & $0.115 \pm 0.04$ & $0.118 \pm 0.03$ & $0.115 \pm 0.04$ & $0.098 \pm 0.03$ & $0.085 \pm 0.02$ \\
\hline \multirow{6}{*}{ RHB } & $\mathrm{AC}$ & $0.140 \pm 0.04$ & $0.141 \pm 0.05$ & $0.158 \pm 0.05$ & $0.158 \pm 0.05$ & $0.154 \pm 0.06$ & $0.150 \pm 0.06$ & $0.163 \pm 0.05$ & $0.156 \pm 0.05$ \\
\hline & $\mathrm{AP}$ & $0.142 \pm 0.05$ & $0.140 \pm 0.05$ & $0.160 \pm 0.05$ & $0.157 \pm 0.05$ & $0.154 \pm 0.05$ & $0.148 \pm 0.05$ & $0.159 \pm 0.06$ & $0.146 \pm 0.05$ \\
\hline & $\mathrm{AV}$ & $0.148 \pm 0.06$ & $0.142 \pm 0.06$ & $0.146 \pm 0.06$ & $0.157 \pm 0.35$ & $0.144 \pm 0.05$ & $0.152 \pm 0.06$ & $0.145 \pm 0.06$ & $0.125 \pm 0.06$ \\
\hline & $\mathrm{BC}$ & $0.149 \pm 0.04$ & $0.151 \pm 0.04$ & $0.163 \pm 0.04$ & $0.170 \pm 0.05$ & $0.154 \pm 0.05$ & $0.158 \pm 0.05$ & $0.169 \pm 0.05$ & $0.164 \pm 0.05$ \\
\hline & BP & $0.141 \pm 0.05$ & $0.140 \pm 0.05$ & $0.160 \pm 0.05$ & $0.159 \pm 0.06$ & $0.151 \pm 0.05$ & $0.152 \pm 0.06$ & $0.157 \pm 0.06$ & $0.145 \pm 0.06$ \\
\hline & BV & $0.155 \pm 0.05$ & $0.146 \pm 0.05$ & $0.156 \pm 0.04$ & $0.162 \pm 0.05$ & $0.155 \pm 0.06$ & $0.155 \pm 0.06$ & $0.162 \pm 0.07$ & $0.139 \pm 0.06$ \\
\hline
\end{tabular}

Note. Values represent mean \pm standard deviation $(\mathrm{N}=30)$.

${ }^{z} \mathrm{EEG}=$ Electroencephalography; $\mathrm{RT}=$ relative theta power spectrum; RLB = relative low-beta power spectrum; RMB = relative mid-beta power spectrum; RHB = relative high-beta power spectrum.

${ }^{\mathrm{y}} \mathrm{F}=$ frontal lobes; $\mathrm{T}=$ temporal lobes; $\mathrm{P}=$ parietal lobes; $\mathrm{O}=$ occipital lobes; odd and even numbers indicate left and right hemispheres, respectively.

spectrum $(\mathrm{RMB})$ in the frontal lobe on the right hemisphere, the parietal lobe on the left hemisphere and the occipital lobe on the left hemisphere, and a significantly lower ratio of mid beta to theta (RMT) in the parietal lobe on the left hemisphere $(p<.05)$ (Tables 3 and 4; Figure 3). The level of RT and RAHB increased more when real 'Silver Queen' plants with green colors were shown to subjects than when the photos of 'Angel' plants with red colors were shown to subjects, which indicates that looking at green plants is effective in increasing a sense of calmness and psychological stability. In addition, the results were similar to the result of Küller et al. (2009) that blue-green and green colors are reported to be effective for psychological stability and relaxation, which indicates that the visual stimuli of the photos of 'Angel' plants are more effective for attention than real 'Silver Queen' plants, but that they also increase the level of strain. Meanwhile, while looking at the photos of 'Angel' plants, the level of relative high-beta power spectrum (RHB) and brain activity (spectral edge frequency 95\%: SEF95) increased more significantly in the occipital lobe on the right hemisphere (Tables 2-4; Figure 3). As the results of the comparison of real 'Silver Queen' plants and the photos of 'Silver Queen' plants or the color scheme of 'Silver Queen' plants showed, these results can be interpreted that the photos of 'Angel' plants made the cerebrum activated more under a high level of stress or strain than real 'Silver Queen' plants. 
Table 3. Overall comparison of electroencephalography results for subjects when viewing color scheme of Aglaonema 'Silver Queen' (AC), color image of $A$. 'Silver Queen' (AP), real $A$. 'Silver Queen' plants (AV), color scheme of $A$. 'Angel' (BC), color image of $A$. 'Angel' (BP), and real $A$. 'Angel' plants (BV)

\begin{tabular}{|c|c|c|c|c|c|c|c|c|c|}
\hline $\mathrm{EEG}^{\mathrm{z}}$ & Color & $F 3^{y}$ & F4 & $\mathrm{T} 3$ & $\mathrm{~T} 4$ & P3 & P4 & $\mathrm{O} 1$ & $\mathrm{O} 2$ \\
\hline \multirow{6}{*}{ RST } & $\mathrm{AC}$ & $0.179 \pm 0.09$ & $0.173 \pm 0.09$ & $0.339 \pm 0.16$ & $0.314 \pm 0.15$ & $0.391 \pm 0.08$ & $0.366 \pm 0.20$ & $0.443 \pm 0.22$ & $0.425 \pm 0.22$ \\
\hline & $\mathrm{AP}$ & $0.182 \pm 0.11$ & $0.172 \pm 0.11$ & $0.368 \pm 0.19$ & $0.327 \pm 0.20$ & $0.401 \pm 0.20$ & $0.402 \pm 0.32$ & $0.399 \pm 0.18$ & $0.318 \pm 0.12$ \\
\hline & AV & $0.208 \pm 0.13$ & $0.187 \pm 0.12$ & $0.332 \pm 0.20$ & $0.325 \pm 0.23$ & $0.380 \pm$ & $0.357 \pm$ & 0.353 & 0.292 \\
\hline & $\mathrm{BC}$ & $0.193 \pm 0.09$ & $0.187 \pm 0.10$ & $0.378 \pm 0.17$ & $0.383 \pm 0.25$ & $0.423 \pm 0.23$ & $0.434 \pm 0.39$ & $0.482 \pm 0.27$ & $0.471 \pm 0.27$ \\
\hline & BP & $0.178 \pm 0.11$ & $0.162 \pm 0.11$ & $0.351 \pm 0.18$ & $0.322 \pm 0.20$ & $0.387 \pm 0.18$ & $0.349 \pm 0.22$ & $0.360 \pm 0.18$ & $0.309 \pm 0.13$ \\
\hline & BV & $0.226 \pm 0.13$ & $0.194 \pm 0.11$ & $0.368 \pm 0.16$ & $0.358 \pm 0.20$ & $0.381 \pm 0.21$ & $0.371 \pm 0.31$ & $0.363 \pm 0.23$ & $0.295 \pm 0.20$ \\
\hline \multirow{6}{*}{ RMT } & $\mathrm{AC}$ & $0.245 \pm 0.12$ & $0.235 \pm 0.12$ & $0.481 \pm 0.24$ & $0.476 \pm 0.29$ & $0.517 \pm 0.25$ & $0.485 \pm 0.23$ & $0.601 \pm 0.37$ & $0.494 \pm 0.22$ \\
\hline & $\mathrm{AP}$ & $0.296 \pm 0.23$ & $0.259 \pm 0.17$ & $0.613 \pm 0.39$ & $0.537 \pm 0.41$ & $0.575 \pm 0.34$ & $0.543 \pm 0.36$ & $0.599 \pm 0.50$ & $0.411 \pm 0.21$ \\
\hline & $\mathrm{AV}$ & $0.272 \pm 0.13$ & $0.261 \pm 0.14$ & $0.464 \pm 0.27$ & $0.500 \pm 0.37$ & $0.432 \pm 0.22$ & $0.467 \pm 0.27$ & $0.462 \pm 0.44$ & $0.315 \pm 0.21$ \\
\hline & $\mathrm{BC}$ & $0.291 \pm 0.15$ & $0.287 \pm 0.15$ & $0.576 \pm 0.36$ & $0.572 \pm 0.38$ & $0.601 \pm 0.37$ & $0.600 \pm 0.39$ & $0.612 \pm 0.27$ & $0.563 \pm 0.25$ \\
\hline & $\mathrm{BP}$ & $0.252 \pm 0.16$ & $0.234 \pm 0.16$ & $0.508 \pm 0.27$ & $0.480 \pm 0.30$ & $0.541 \pm 0.32$ & $0.478 \pm 0.31$ & $0.488 \pm 0.33$ & $0.379 \pm 0.21$ \\
\hline & BV & $0.289 \pm 0.16$ & $0.260 \pm 0.12$ & $0.472 \pm 0.21$ & $0.543 \pm 0.40$ & $0.469 \pm 0.22$ & $0.464 \pm 0.30$ & $0.544 \pm 0.51$ & $0.339 \pm 0.25$ \\
\hline \multirow{6}{*}{ SEF95 } & $\mathrm{AC}$ & $39.119 \pm 5.72$ & $39.134 \pm 5.88$ & $39.615 \pm 5.52$ & 40.565 & $37.035 \pm 5.81$ & $37.065=$ & 40.487 & 40.64 \\
\hline & $\mathrm{AP}$ & $169 \pm 4.87$ & $39.333 \pm 5.39$ & $40.040 \pm 5.93$ & $40.253 \pm 5.67$ & $36.802 \pm 6.25$ & $36.805 \pm 6.28$ & $39.748 \pm 5.70$ & $39.795 \pm 5.62$ \\
\hline & $\mathrm{AV}$ & $38.803 \pm 6.56$ & $39.167 \pm 6.90$ & $38.030 \pm 7.14$ & $40.183 \pm 7.38$ & $36.311 \pm 6.84$ & $36.718 \pm 7.02$ & $39.136 \pm 7.56$ & $37.729 \pm 6.74$ \\
\hline & $\mathrm{BC}$ & $40.151 \pm 4.33$ & $40.435 \pm 4.28$ & $40.301 \pm 5.24$ & $41.357 \pm 5.19$ & $37.321 \pm 6.04$ & $37.529 \pm 6.32$ & $40.601 \pm 4.72$ & $40.800 \pm 4.75$ \\
\hline & $\mathrm{BP}$ & $39.243 \pm 5.38$ & $39.383 \pm 5.42$ & $39.734 \pm 5.69$ & $40.403 \pm 6.01$ & $37.143 \pm 6.03$ & $36.768 \pm 6.22$ & $39.999 \pm 6.12$ & $40.164 \pm 5.83$ \\
\hline & BV & $39.798 \pm 5.31$ & $39.198 \pm 4.97$ & $39.696 \pm 4.90$ & $40.308 \pm 5.77$ & $36.883 \pm 5.46$ & $36.926 \pm 5.52$ & $40.292 \pm 6.04$ & $39.225 \pm 5.82$ \\
\hline \multirow{6}{*}{ RAHB } & $\mathrm{AC}$ & $1.348 \pm 0.73$ & $1.352 \pm 0.86$ & $0.481 \pm 0.25$ & $1.397 \pm 1.04$ & $2.122 \pm 2.22$ & $2.052 \pm 2.17$ & $1.687 \pm 1.23$ & $1.682 \pm 1.22$ \\
\hline & $\mathrm{AP}$ & & & & & & & & $2.058 \pm 2.07$ \\
\hline & $\mathrm{AV}$ & $1.684 \pm 1.60$ & $1.638 \pm 1.46$ & $2.057 \pm 1.93$ & $1.634 \pm 1.48$ & & $2.017 \pm 1.71$ & $2.092 \pm 1.78$ & $2.495 \pm 1.86$ \\
\hline & $\mathrm{BC}$ & $1.325 \pm 0.70$ & $1.134 \pm 0.49$ & $1.666 \pm 1.39$ & $1.332 \pm 1.16$ & $2.317 \pm 3.01$ & $2.083 \pm 2.99$ & $1.708 \pm 1.66$ & $1.709 \pm 1.68$ \\
\hline & BP & $1.391 \pm 0.87$ & $1.294 \pm 0.81$ & $1.633 \pm 1.20$ & $1.420 \pm 1.03$ & $2.094 \pm 1.81$ & $1.979 \pm 1.75$ & $1.800 \pm 1.40$ & $1.861 \pm 1.36$ \\
\hline & $\mathrm{BV}$ & $1.438 \pm 1.08$ & $1.452 \pm 1.02$ & $1.667 \pm 0.92$ & $1.461 \pm 1.03$ & $2.115 \pm 1.56$ & $2.002 \pm 1.56$ & $1.728 \pm 1.36$ & $2.135 \pm 1.58$ \\
\hline
\end{tabular}

Note. Values represent mean \pm standard deviation $(\mathrm{N}=30)$.

${ }^{z} \mathrm{EEG}=$ Electroencephalography; RST $=$ ratio of SMR to theta; RMT = ratio of mid beta to theta; RAHB = ratio of alpha to high beta; SEF95 = spectral edge frequency $95 \%$.

${ }^{\mathrm{y}} \mathrm{F}=$ frontal lobes; $\mathrm{T}=$ temporal lobes; $\mathrm{P}=$ parietal lobes; $\mathrm{O}=$ occipital lobes; odd and even numbers indicate left and right hemispheres, respectively.

The group of real 'Silver Queen' plants with green colors and that of real 'Angel' plants with red colors were compared, and the group of real 'Silver Queen' plants showed a significantly lower level of relative low beta power spectrum (RLB) in the temporal lobe on the left hemisphere than the group of real 'Angel' plants $(p<.05)$. There was no significant difference between the two groups compared to the results of the comparison of the group of real 'Silver Queen' plants and those of the photos of plants or the color schemes of plants displayed on the monitor screen. It was found that 'Angel' plants were effective in increasing attention with a small amount of strain, but that 'Silver' plants with green colors were more effective in increasing stability and relaxation than 'Angel' plants with red colors (Tables 2 and 4; Figure 3).

Lee and Son (1999) reported that real green plants and the visual stimuli of green plant slides increased a sense of comfortability and stability and that red colors showed the highest level of anger and nervousness, and Kim (1997) and Wells (1997) reported that green was the most effective color for psychological stability. As these studies showed, the results of this study can be interpreted that green colors have a more positive impact on the physiological conditions of humans in a stable and relaxed state. Li et al. (2012) also reported that subjects who saw sceneries of green plants tended to experience less fatigue and anxiety and higher vitality than those who looked at sceneries of red and yellow plants, and 
Table 4. Cross-color comparison of electroencephalography results for subjects when viewing color scheme of Aglaonema 'Silver Queen' (AC), color image of $A$. 'Silver Queen' (AP), real $A$. 'Silver Queen' plants (AV), color scheme of $A$. 'Angel' (BC), color image of $A$. 'Angel' (BP), and real $A$. 'Angel' plants (BV)

\begin{tabular}{|c|c|c|c|c|c|c|c|c|c|}
\hline $\mathrm{EEG}^{\mathrm{z}}$ & Color & $\mathrm{F}^{\mathrm{y}}$ & $\mathrm{F} 4$ & T3 & $\mathrm{T} 4$ & P3 & P4 & $\mathrm{O} 1$ & $\mathrm{O} 2$ \\
\hline \multirow{5}{*}{$\mathrm{RT}$} & $\mathrm{AV}$ vs. AC & -0.983 & -1.344 & 1.439 & 0.102 & 1.871 & 1.051 & $2.677^{*}$ & $4.994^{* * * *}$ \\
\hline & AV vs. AP & -0.513 & -0.819 & $2.646^{*}$ & 0.157 & $2.416^{*}$ & 1.130 & $2.132^{*}$ & $2.679^{*}$ \\
\hline & AV vs. BC & 0.530 & 0.464 & $2.542^{*}$ & 1.920 & $2.374^{*}$ & $2.545^{*}$ & $3.230^{* *}$ & $4.156^{* * *}$ \\
\hline & AV vs. BP & -1.225 & -1.288 & 1.426 & -0.125 & 1.333 & 0.415 & 1.292 & $2.561^{*}$ \\
\hline & AV vs. BV & 0.978 & 0.339 & 1.234 & 0.881 & 1.132 & 0.616 & 1.066 & 1.046 \\
\hline \multirow{5}{*}{ RLB } & AV vs. AC & 0.489 & -0.240 & -0.387 & -0.752 & -0.200 & -0.869 & -1.524 & -1.294 \\
\hline & AV vs. AP & $2.400^{*}$ & 1.013 & 0.355 & -0.929 & -0.154 & -0.855 & -0.868 & 0.023 \\
\hline & AV vs. BC & 0.555 & -0.289 & -1.038 & -1.580 & -0.870 & -1.235 & $-2.244^{*}$ & -1.379 \\
\hline & AV vs. BP & 1.821 & 1.917 & 0.253 & -0.035 & 0.335 & 0.072 & -0.285 & 0.287 \\
\hline & AV vs. BV & -1.441 & -1.726 & $-2.340^{*}$ & -1.618 & -1.119 & -0.486 & 0.081 & 0.361 \\
\hline \multirow{5}{*}{ RMB } & AV vs. AC & 0.630 & 0.612 & -0.749 & -0.736 & -1.926 & -0.980 & $-4.663^{* * * *}$ & $-4.486^{* * *}$ \\
\hline & AV vs. AP & -0.487 & 0.320 & $-2.456^{*}$ & -1.625 & -2.002 & -0.959 & $-3.905^{*}$ & $-2.628^{*}$ \\
\hline & AV vs. BC & -1.371 & -1.753 & $-2.500^{*}$ & -2.000 & $-3.200^{* *}$ & $-2.386^{*}$ & $-4.894^{* * * *}$ & $-3.946^{* * *}$ \\
\hline & AV vs. BP & 1.404 & $2.163^{*}$ & -0.548 & -0.195 & $-2.175^{*}$ & 0.112 & $-2.448^{*}$ & -1.034 \\
\hline & AV vs. BV & -0.093 & -0.775 & -0.856 & -1.156 & -1.073 & 0.470 & -0.873 & 1.384 \\
\hline \multirow{5}{*}{ RHB } & AV vs. AC & 0.831 & 0.089 & -1.337 & -0.068 & -1.067 & 0.276 & -1.721 & $-3.406^{* *}$ \\
\hline & AV vs. AP & 0.463 & 0.155 & -1.318 & 0.029 & -0.913 & 0.372 & -1.389 & $-2.306^{*}$ \\
\hline & AV vs. BC & -0.108 & -0.901 & -1.698 & -1.322 & -1.037 & -0.559 & $-2.149^{*}$ & $-3.362^{* *}$ \\
\hline & AV vs. BP & 0.757 & 0.228 & -1.401 & -0.191 & 0.834 & 0.010 & -1.228 & $-2.368^{*}$ \\
\hline & AV vs. BV & -0.784 & -0.463 & -1.018 & -0.478 & -1.038 & -0.273 & -1.627 & -1.401 \\
\hline \multirow{5}{*}{ RST } & AV vs. AC & 1.243 & 0.924 & -0.296 & 0.294 & -0.270 & -0.229 & -1.972 & $-3.321^{* *}$ \\
\hline & AV vs. AP & 1.130 & 0.670 & -1.178 & -0.068 & -0.658 & -0.774 & -0.964 & -0.451 \\
\hline & AV vs. BC & 0.635 & -0.023 & -1.458 & $-2.128^{*}$ & -0.766 & -1.162 & $-2.205^{*}$ & $-2.854^{* *}$ \\
\hline & AV vs. BP & 1.182 & 1.133 & -0.516 & 0.118 & -0.117 & 0.159 & -0.128 & -0.312 \\
\hline & AV vs. BV & -1.123 & -0.640 & -1.302 & -0.997 & -0.353 & -0.449 & -0.326 & -0.083 \\
\hline \multirow{5}{*}{ RMT } & AV vs. AC & 1.372 & 1.383 & -0.335 & 0.385 & $-2.450^{*}$ & -0.436 & $-2.250^{*}$ & $-4.288^{* * *}$ \\
\hline & AV vs. AP & -0.717 & 0.072 & $-2.386^{*}$ & -0.570 & $-2.793^{* *}$ & -1.320 & $-2.504^{*}$ & $-2.142^{*}$ \\
\hline & AV vs. BC & -0.851 & -1.261 & -1.837 & -1.412 & $-3.411^{* *}$ & $-2.767^{*}$ & $-2.103^{*}$ & $-4.220^{* * * *}$ \\
\hline & AV vs. BP & 0.705 & 1.194 & -0.838 & 0.372 & $-2.137^{*}$ & -0.214 & -0.457 & -1.780 \\
\hline & AV vs. BV & -0.803 & 0.053 & -0.187 & -0.743 & -1.237 & 0.056 & -1.715 & -0.482 \\
\hline \multirow{5}{*}{ SEF95 } & AV vs. AC & -0.268 & 0.031 & -1.500 & -0.357 & -0.656 & -0.326 & -1.373 & $-3.056^{* *}$ \\
\hline & AV vs. AP & -0.287 & -0.123 & -1.661 & -0.052 & -0.382 & -0.065 & -0.465 & -1.790 \\
\hline & AV vs. BC & -1.064 & -1.057 & -1.682 & -0.921 & -0.740 & -0.611 & -1.264 & $-2.381^{*}$ \\
\hline & AV vs. BP & -0.401 & -0.217 & -1.687 & -0.209 & -0.806 & -0.051 & -0.728 & $-2.598^{*}$ \\
\hline & AV vs. BV & -0.958 & -0.028 & -1.354 & -0.102 & -0.473 & -0.170 & -1.023 & -1.349 \\
\hline \multirow{5}{*}{ RAHB } & AV vs. AC & 1.286 & 1.202 & $4.376^{* * *}$ & 0.939 & 0.377 & 0.048 & 1.595 & $2.407^{*}$ \\
\hline & AV vs. AP & 0.815 & 0.561 & 1.146 & 0.222 & -0.213 & -0.300 & 0.375 & 1.054 \\
\hline & AV vs. BC & 1.469 & $2.044^{*}$ & 1.229 & 0.995 & -0.072 & -0.020 & 1.065 & 1.848 \\
\hline & AV vs. BP & 1.397 & 1.709 & 1.815 & 0.903 & 0.719 & 0.356 & 1.203 & $2.249^{*}$ \\
\hline & AV vs. BV & 1.340 & 0.878 & 1.351 & 0.718 & 0.619 & 0.257 & 1.249 & 1.518 \\
\hline
\end{tabular}

${ }^{\mathrm{z}} \mathrm{EEG}=$ Electroencephalography; $\mathrm{RT}=$ relative theta power spectrum; RLB = relative low-beta power spectrum; RMB = relative mid-beta power spectrum; RHB = relative high-beta power spectrum, $\mathrm{RST}=$ ratio of SMR to theta; RMT $=$ ratio of mid beta to theta, $\mathrm{RAHB}=$ ratio of alpha to high beta, SEF95 = spectral edge frequency $95 \%$.

${ }^{\mathrm{y}} \mathrm{F}=$ frontal lobes; $\mathrm{T}=$ temporal lobes; $\mathrm{P}=$ parietal lobes; $\mathrm{O}=$ occipital lobes; odd and even numbers indicate left and right hemispheres, respectively.

${ }^{*} p<.05,{ }^{* *} p<.01,{ }^{* * *} p<.001$ by paired t-test. 


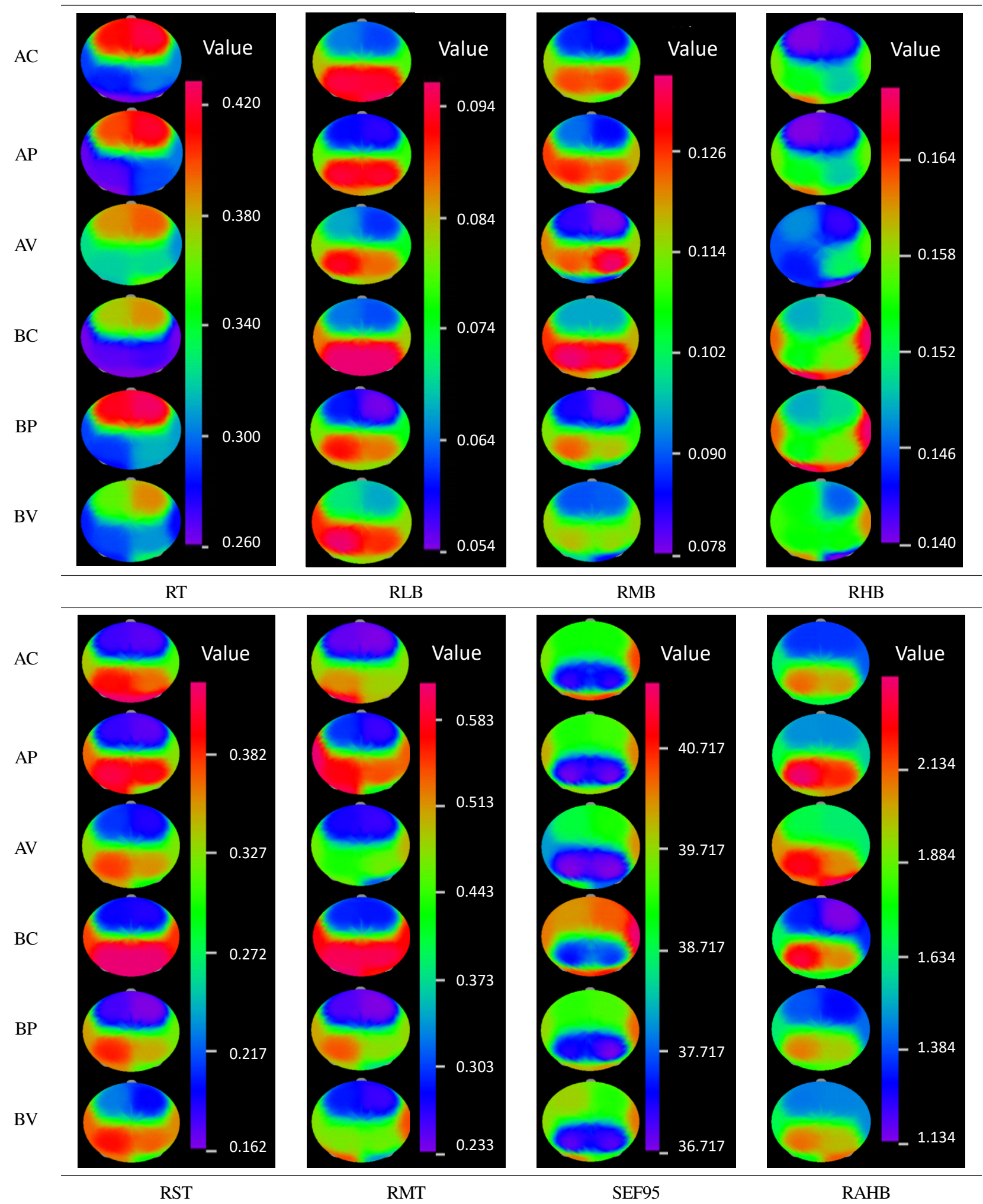

Figure 3. Electroencephalographic (EEG) mapping: blue and red indicate low and high electrical potential, respectively. Comparison of EEG voltages observed in response to (AC) color scheme of Aglaonema 'Silver Queen,' (AP) color image of $A$. 'Silver Queen,' (AV) $A$. 'Silver Queen' plants, (BC) color scheme of $A$. 'Angel,' (BP) color image of $A$. 'Angel,' (BV) $A$. 'Angel' plants. RT = Relative theta power spectrum; RLB = relative low-beta power spectrum; $\mathrm{RMB}=$ relative mid-beta power spectrum; $\mathrm{RHB}=$ relative high-beta power spectrum; $\mathrm{RST}$ = ratio of SMR to theta; $\mathrm{RMT}=$ ratio of mid beta to theta; SEF95 = spectral edge frequency $95 \%$; RAHB = ratio of alpha to high beta. 
this study also supports the finding of this study that 'Silver Queen' plants with green colors were effective for stability and relaxation than 'Angel' plants with red colors. The result that 'Angel' plants with red colors showed a significantly higher level of beta waves (RMB and RHB) than 'Silver Queen' plants with green colors, which indicates that plants with red colors are perceived as something new and interesting as Sokolov (1963) reported that beta waves increased when new or interesting visual stimuli are perceived. However, Jang et al. (2014) that compared one-colored flowers (green or red) showed conflicting results with those of this study that compared multi-colored plants, which needs to be identified through follow-up studies.

\section{Changes in the autonomic nervous system caused by the color stimuli of two types of foliage plants}

The heart rate per minute in six groups (natural colors of real plants of two varieties; artificial colors of the photos of the same plants; color schemes of plants produced based on the color ratio of the leaves) were similar (67-69 beats). In addition, norm LF (LF power in normalized units: LF/LF+HF), an indicator of the activity of the sympathetic nervous system, and norm HF (HF power in normalized units: HF/LF+HF), an indicator of the activity of the parasympathetic nervous system did not show any significant difference (Figure 4). Although statistically not significant, the average heart rate of the group of real 'Angel' plants was the highest among other groups. Norm LF of which value increases in a state of strain was the highest in the group of the color scheme of 'Silver Queen' plants, and norm HF of which value increases in a state of relaxation tended to be high in the groups of real 'Silver Queen' plants and the color scheme of 'Angel' plants, but they were not statistically significant.

\section{Analysis of responses to the psychological questionnaire about emotional words}

The responses to the psychological questionnaire on 14 pairs of emotional words to six color stimuli of two varieties of foliage plants were analyzed and the results are as shown in Table 5. Subjects showed "clam" and "comfortable" feelings strongly to the groups of the photos of 'Silver Queen' plants and the color scheme of 'Silver Queen' plants with green colors. The group of real 'Silver Queen' plants showed a high level of "bright," "sophisticated" and "comfortable" feelings. The group of the color scheme of "Angel' plants showed "heavy," "strong" and "uneasy" feelings, while the groups of the photos of 'Angel' plants and real "Angel' plants showed high scores in "strong" and "fancy" feelings. The group of the photo of 'Silver Queen' plants with green colors was found to be distributed more on the right side of emotional words including "comfortable," "bright" and "calm" than the group of the photo of 'Angel' plants with red colors, which were
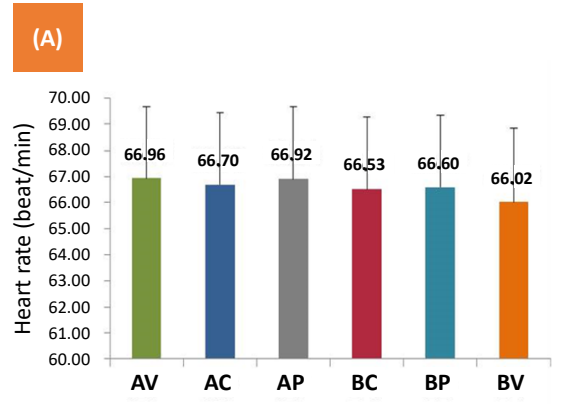
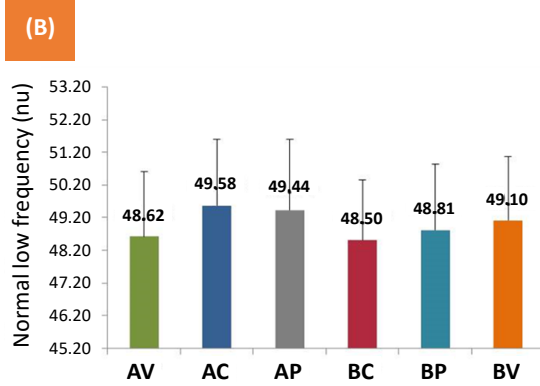
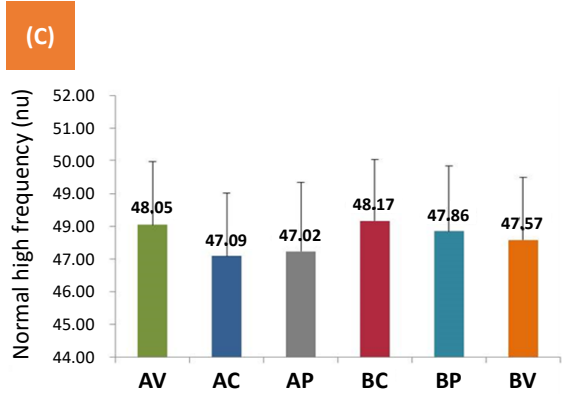

Figure 4. Changes in heart rate (A), the sympathetic nerve (B), and the parasympathetic nerve (C) in response to stimuli of two foliage plants: (AV) real Aglaonema 'Silver Queen' plants, (AC) color scheme of $A$. 'Silver Queen,' (AP) color image of $A$. 'Silver Queen,' (BC) color scheme of $A$. 'Angel,' (BP) color image of $A$. 'Angel,' (BV) real $A$. 'Angel' plants. 
Table 5. Semantic differential scale used by subjects to describe color scheme of Aglaonema ‘Silver Queen' (AC), color image of $A$. 'Silver Queen' (AP), real $A$. 'Silver Queen' plants (AV), color scheme of $A$. 'Angel' (BC), color image of $A$. 'Angel' (BP), and real A. 'Angel' plants (BV)

\begin{tabular}{|c|c|c|c|c|c|c|c|c|}
\hline \multirow{2}{*}{$\mathrm{V}^{\mathrm{z}}$} & \multicolumn{6}{|c|}{ Treatment (color) } & \multirow{2}{*}{$\mathrm{F}$} & \multirow{2}{*}{$p$} \\
\hline & $\mathrm{AC}$ & AP & $\mathrm{AV}$ & $\mathrm{BC}$ & $\mathrm{BP}$ & $\mathrm{BV}$ & & \\
\hline $\mathrm{B} 1$ & $2.67 \pm 1.06 \mathrm{a}^{\mathrm{y}}$ & $3.97 \pm 0.76 b c$ & $4.17 \pm 0.87 \mathrm{c}$ & $2.73 \pm 1.11 \mathrm{a}$ & $3.27 \pm 1.08 \mathrm{ab}$ & $3.80 \pm 0.92 \mathrm{bc}$ & 12.944 & $.001^{* * * *}$ \\
\hline B2 & $3.13 \pm 1.11 \mathrm{ab}$ & $4.10 \pm 0.80 \mathrm{c}$ & $3.83 \pm 1.20 \mathrm{bc}$ & $2.67 \pm 1.09 \mathrm{a}$ & $3.50 \pm 0.90 \mathrm{bc}$ & $3.83 \pm 0.75 \mathrm{bc}$ & 8.628 & $.001^{* * *}$ \\
\hline B3 & $2.73 \pm 0.98 \mathrm{abc}$ & $3.60 \pm 0.86 \mathrm{~d}$ & $3.50 \pm 1.04 \mathrm{~cd}$ & $2.13 \pm 1.01 \mathrm{a}$ & $2.40 \pm 0.97 \mathrm{ab}$ & $3.10 \pm 1.03 \mathrm{bcd}$ & 10.909 & $.001^{* * * *}$ \\
\hline B4 & $3.00 \pm 1.02 \mathrm{a}$ & $3.10 \pm 1.06 \mathrm{a}$ & $2.97 \pm 1.19 \mathrm{a}$ & $3.33 \pm 1.09 \mathrm{ab}$ & $3.70 \pm 1.06 \mathrm{ab}$ & $4.10 \pm 0.88 \mathrm{~b}$ & 5.484 & $.001^{* * * *}$ \\
\hline B5 & $3.90 \pm 1.06 \mathrm{c}$ & $3.40 \pm 0.89 \mathrm{abc}$ & $3.30 \pm 1.09 \mathrm{abc}$ & $3.50 \pm 1.25 \mathrm{bc}$ & $2.60 \pm 1.19 \mathrm{a}$ & $2.70 \pm 1.09 \mathrm{ab}$ & 6.097 & $.001^{* * * *}$ \\
\hline B6 & $3.13 \pm 0.97 \mathrm{c}$ & $3.17 \pm 1.02 \mathrm{c}$ & $3.03 \pm 1.19 \mathrm{bc}$ & $2.23 \pm 1.10 \mathrm{a}$ & $2.20 \pm 0.92 \mathrm{a}$ & $2.30 \pm 0.92 \mathrm{ab}$ & 6.510 & $.001^{* * * *}$ \\
\hline B7 & $3.37 \pm 1.25 \mathrm{a}$ & $4.03 \pm 0.81 \mathrm{a}$ & $3.70 \pm 1.06 \mathrm{a}$ & $3.67 \pm 1.15 \mathrm{a}$ & $3.57 \pm 1.10 \mathrm{a}$ & $3.77 \pm 1.10 \mathrm{a}$ & 1.238 & .293 \\
\hline B8 & $2.80 \pm 1.19 a$ & $3.40 \pm 1.22 \mathrm{ab}$ & $3.63 \pm 1.10 \mathrm{ab}$ & $3.33 \pm 1.21 \mathrm{ab}$ & $3.83 \pm 0.83 b$ & $3.90 \pm 1.24 \mathrm{~b}$ & 3.757 & $.003^{* *}$ \\
\hline B9 & $2.57 \pm 1.14 \mathrm{a}$ & $4.13 \pm 1.04 \mathrm{~b}$ & $3.63 \pm 1.25 \mathrm{~b}$ & $3.50 \pm 1.38 \mathrm{~b}$ & $3.50 \pm 1.31 \mathrm{~b}$ & $3.77 \pm 1.14 \mathrm{~b}$ & 5.540 & $.001^{* * * *}$ \\
\hline B10 & $3.27 \pm 1.17 \mathrm{a}$ & $4.00 \pm 0.91 \mathrm{ab}$ & $4.07 \pm 0.94 b$ & $3.60 \pm 1.16 \mathrm{ab}$ & $3.43 \pm 1.04 \mathrm{ab}$ & $3.93 \pm 0.94 \mathrm{ab}$ & 2.873 & $.016^{*}$ \\
\hline B11 & $3.40 \pm 1.16 \mathrm{ab}$ & $4.13 \pm 0.82 \mathrm{~b}$ & $3.90 \pm 0.99 \mathrm{ab}$ & $3.33 \pm 1.18 \mathrm{a}$ & $3.43 \pm 1.14 \mathrm{ab}$ & $3.77 \pm 1.04 \mathrm{ab}$ & 2.752 & $.020^{*}$ \\
\hline B12 & $4.00 \pm 0.83 b$ & $4.20 \pm 0.76 \mathrm{~b}$ & $3.70 \pm 0.99 b$ & $3.70 \pm 0.79 b$ & $2.93 \pm 1.01 \mathrm{a}$ & $2.90 \pm 1.16 \mathrm{a}$ & 10.098 & $.001^{* * *}$ \\
\hline B13 & $3.90 \pm 0.88 \mathrm{bc}$ & $4.23 \pm 0.68 \mathrm{c}$ & $3.93 \pm 0.98 \mathrm{bc}$ & $3.10 \pm 1.06 \mathrm{a}$ & $3.27 \pm 0.94 \mathrm{ab}$ & $3.43 \pm 1.01 \mathrm{ab}$ & 6.732 & $.001^{* * *}$ \\
\hline B14 & $2.47 \pm 1.07 \mathrm{a}$ & $2.90 \pm 1.06 \mathrm{a}$ & $2.97 \pm 1.60 \mathrm{a}$ & $3.20 \pm 1.19 \mathrm{abc}$ & $3.80 \pm 1.03 \mathrm{bc}$ & $4.07 \pm 1.11 \mathrm{c}$ & 8.774 & $.001^{* * * *}$ \\
\hline
\end{tabular}

Note. For semantic differential, 1(left) to 5(right).

${ }^{\mathrm{z}} \mathrm{V}$ = Variance; B1 = dark-bright; B2 = hard-soft; B3 = heavy-light; B4 = cool-warm; B5 = complicated-simple; B6 = strong-pale; B7 = cheapluxurious; $\mathrm{B} 8$ = commonplace-unique; $\mathrm{B} 9=$ restrained-sharp; $\mathrm{B} 10$ = provincial-sophisticated; $\mathrm{B} 11$ = unpleasant-pleasant; $\mathrm{B} 12=$ vibrant-calm; $\mathrm{B} 13=$ uneasy-comfortable; $\mathrm{B} 14=$ modest-fancy.

${ }^{y}$ Mean separation within columns by Tukey's multiple range test, $5 \%$ level $(\mathrm{N}=30)$.

${ }^{*} p<.05,{ }^{* * *} p<.01,{ }^{* * *} p<.001$ by one way ANOVA. Mean \pm standard deviation $(\mathrm{N}=30)$.

similar to the results of the following studies. Jang et al. (2015) examined color sensitivity to the color and shape of plants used in green interior and reported that the group of green stimuli tended to show "calm" and "comfortable" feelings strongly and that the group of red stimuli tended to show "strong" and "fancy" feelings strongly. Wang (2008) reported that subjects strongly sensed the red color of cut-flowers, and Küller et al. (2009) also found that red colors and patterns stimulated the brain more. In addition, Jang et al. (2014) measured changes in EEG depending on the color of pot flowers and showed similar results to those of this study. Based on the results of this study, it can be concluded that red colors tend to induce "strong," "uneasy" and "fancy" feelings.

\section{Correlation between EEG and emotional words}

The correlation between EEG and emotional words in six color stimuli of two varieties of foliage plants was analyzed (Table 6), and real 'Silver Queen' plants with green colors (control group) showed a positive correlation with RHB in the emotional words of "commonplace-unique." This can be interpreted that as the RHB of real 'Silver Queen' plants increases, subjects tend to move to "unique (right side)," and as RHB decreases, subjects tend to move to "ordinary (left side)." In addition, real 'Silver Queen' plants with green colors (control group) showed a negative correlation with RST and RLB in the emotional words of "provincial-sophisticated." As RST and RLB increase, subjects tend to move to "provincial." The color scheme of 'Silver Queen' plants with green colors showed a positive correlation with RMB in the 
Table 6. Relationship between EEG and semantic differential scale in six color stimuli of Aglaonema 'Silver Queen' and $A$. 'Angel'

\begin{tabular}{|c|c|c|c|c|c|c|c|c|c|c|c|c|c|c|}
\hline $\mathrm{EEG}^{\mathrm{z}}$ & $\mathrm{B} 1^{\mathrm{y}}$ & B2 & B3 & B4 & B5 & B6 & B7 & B8 & B9 & B10 & B11 & B12 & B13 & B14 \\
\hline \multicolumn{15}{|c|}{ Aglaonema 'Silver Queen' color scheme } \\
\hline RMB & .333 & .293 & .031 & .299 & -.301 & -.061 & .114 & $.383^{*}$ & .164 & .310 & $.383^{*}$ & -.153 & -.029 & .292 \\
\hline \multicolumn{15}{|c|}{ Aglaonema 'Silver Queen' color image } \\
\hline RMB & .009 & -.081 & -.179 & .344 & .133 & -.015 & .024 & .187 & .287 & .135 & .009 & .017 & .062 & $.366^{* *}$ \\
\hline \multicolumn{15}{|c|}{ Aglaonema 'Silver Queen' plants } \\
\hline RLB & -.061 & .038 & .123 & .115 & .005 & .168 & -.257 & -.334 & -.093 & $-.406^{*}$ & -.226 & -.223 & -.286 & -.107 \\
\hline RHB & .042 & -.137 & .028 & -.044 & .084 & .002 & .161 & $.376^{*}$ & .017 & .227 & .181 & .065 & .054 & -.136 \\
\hline RST & -.066 & -.050 & .127 & .142 & .052 & .192 & -.304 & -.221 & -.101 & $-.388^{*}$ & -.209 & -.197 & -.283 & -.169 \\
\hline \multicolumn{15}{|c|}{ Aglaonema 'Angel' color scheme } \\
\hline RT & -.236 & .022 & -.040 & -.110 & .146 & -.006 & $-.384^{*}$ & .111 & -.243 & $-.396^{*}$ & $-.426^{*}$ & -.046 & -.193 & -.077 \\
\hline RLB & .224 & .320 & .287 & .310 & .076 & $.546^{* *}$ & .011 & .157 & .126 & .017 & .031 & -.183 & .060 & .193 \\
\hline RST & .258 & .224 & .263 & .287 & .007 & $.442^{*}$ & .170 & .050 & .121 & .191 & .216 & -.122 & .125 & .108 \\
\hline \multicolumn{15}{|c|}{ Aglaonema 'Angel' color image } \\
\hline RT & .145 & -.003 & $-.508^{* *}$ & -.100 & .058 & -.256 & .027 & -.211 & .080 & .032 & .058 & .007 & .025 & -.099 \\
\hline RLB & .344 & $.427^{*}$ & $.475^{*}$ & .170 & .241 & .356 & .199 & .263 & .252 & .305 & .264 & .027 & .316 & .261 \\
\hline RMB & .151 & .291 & .250 & .284 & $.400^{*}$ & .221 & .257 & .227 & .199 & .336 & $.395^{*}$ & .152 & .275 & $.386^{*}$ \\
\hline RST & .261 & .182 & .184 & .340 & .174 & -.060 & .204 & .289 & $.364^{*}$ & .303 & $.425^{*}$ & .207 & .135 & .200 \\
\hline RMT & .075 & -.004 & .080 & .340 & .174 & -.129 & .134 & .217 & .211 & .182 & $.370^{*}$ & .211 & .028 & .161 \\
\hline SEF95 & .137 & .054 & $-.379^{*}$ & .152 & .123 & -.358 & .092 & -.053 & .082 & .071 & .167 & .109 & .102 & .112 \\
\hline \multicolumn{15}{|c|}{ Aglaonema 'Angel' plants } \\
\hline RLB & $-.495^{* *}$ & $-.479^{* *}$ & $-.364^{*}$ & $-.370^{*}$ & .204 & -.076 & -.246 & $-.370^{*}$ & .120 & -.356 & -.233 & -.030 & -.267 & -.273 \\
\hline RMB & .023 & .162 & $.386^{*}$ & $.383^{*}$ & .161 & .312 & .334 & .263 & -.079 & .144 & .251 & .185 & .134 & .159 \\
\hline RHB & .162 & .084 & .300 & .240 & .193 & -.002 & .172 & .055 & $-.371^{*}$ & .038 & -.029 & .142 & .173 & -.230 \\
\hline RST & $-.382^{*}$ & $-.384^{*}$ & -.209 & -.226 & .291 & -.146 & -.174 & -.276 & -.069 & -.307 & .213 & -.007 & -.200 & $-.391^{*}$ \\
\hline RAHB & -.309 & -.184 & $-.390^{*}$ & -.321 & -.057 & -.130 & -.208 & -.168 & .278 & -.127 & -.023 & -.131 & -.184 & -.031 \\
\hline
\end{tabular}

${ }^{\mathrm{z}} \mathrm{EEG}=$ Electroencephalography; RT = relative theta power spectrum; RLB = relative low beta power spectrum; RMB = relative mid beta power spectrum; RHB = relative high beta power spectrum; RST = ratio of SMR to theta; RMT = ratio of mid beta to theta; SEF95 = spectral edge frequency $95 \% ; \mathrm{RAHB}=$ ratio of alpha to high beta.

${ }^{\mathrm{y}} \mathrm{B} 1$ = dark-bright; B2 = hard-soft; B3 = heavy-light; B4 = cool-warm; B5 = complicated-simple; B6 = strong-pale; B7=cheap-luxurious; B8 = commonplace-unique; $\mathrm{B} 9=$ restrained-sharp; $\mathrm{B} 10=$ provincial-sophisticated; $\mathrm{B} 11=$ unpleasant-pleasant; $\mathrm{B} 12=$ vibrant-calm; $\mathrm{B} 13=$ uneasy-comfortable; B14 = modest-fancy.

${ }^{*} p<.05,{ }^{* *} p<.01,{ }^{* * *} p<.001(\mathrm{~N}=30)$.

emotional words of "commonplace-unique" and "unpleasant-pleasant," which indicates that as the RMB of the color scheme of 'Silver Queen' plants decreases, subjects tend to have "commonplace" and "unpleasant" feelings more. The photo of 'Silver Queen' plants showed a positive correlation with RMB in "modest-fancy," which indicates that as the RMB of the photo of 'Silver Queen' plants decreases, subjects tend to move to "modest."

The color scheme of 'Angel' plants with red colors showed a negative correlation with RT in the emotional words of "cheap-luxurious," "provincial-sophisticated" and "unpleasant-pleasant," and a positive correlation with RLB and 
RST in "strong-pale." This can be interpreted that the color scheme of "Angel' plants with red colors tends to move to "luxurious," "sophisticated" and "like" as RT decreases, and that it tends to move to "pale" as RLB and RST decrease. These results are similar to the results of Jang et al. (2014) on the correlation between the EEG of the red stimuli group and emotional words.

The photo of 'Angel' plants with red colors showed a negative correlation with RT and SEF95 in the emotional words of "heavy-light," and a positive correlation with RLB in "hard-soft" and "heavy-light,"and RMB in "complicated-simple," "unpleasant-pleasant" and "modest-fancy." In addition, it showed a positive correlation with RST in "restrained-sharp" and "unpleasant-pleasant," and with RMT in "unpleasant-pleasant." These results indicate that as RT and SEF95 (brain activity) increase, subjects tend to move to "heavy," and that as RLB decreases, they tend to move to "hard." In addition, as RMB decreases, subjects tend to have "complicated," "unpleasant" and "modest" feelings more, and as RST and RMT decrease, they tend to move to "unpleasant."

Real 'Angel' plants with red colors showed a negative correlation with RLB in "dark-bright," "hard-soft," "heavy-light," "cool-warm" and "commonplace-unique," and a positive correlation with RMB in "heavy-light" and "cool-warm." They also showed a negative correlation with RHB in "restrained-sharp"; RST in "dark-bright," "hard-soft" and "modest-fancy"; and RAHB in "heavy-light" ( $p<.05)$. These results indicate that as RLB decreases, subjects tend to have "bright," "soft," "light," "warm" and "unique" feelings more, and that as RMB increases, they tend to have "light" and "warm" feelings. As RHB decreases, they tend to move to "sharp," and as RST decreases, they tend to have "bright," "soft" and "fancy" feelings. As RAHB decreases, they tend to move to "light." In addition, the groups of "Angel' plants with red colors were found to show a high correlation a statistically significantly high correlation with EEG compared to those of "Silver Queen' plants with green colors.

\section{Conclusion}

To examine the effects of the color stimuli of the leaves of two varieties of a foliage plant on changes in physiological conditions, this study measured electroencephalogram (EEG) and electrocardiogram (ECG) and conducted a psychological response test, targeting a total of 30 subjects in their 50s or older. The physiological response test to six color stimuli was carried out. The group of real Aglaonemas 'Silver Queen' plants with green colors was set as the control group, and was compared with other groups one by one including the group of real Aglaonemas 'Angel' plants (red colors) and four groups of artificial colors (two photos of the same plants, two color scheme images of the same plants). The real 'Silver Queen' plants with green colors showed a higher level of relative theta power spectrum (RT) and a higher ratio of alpha to high beta (RAHB) than the rest five color stimuli, which can be attributed to the fact that internal concentration can be increased in a state of stability and relaxation under an appropriate level of awakening. Between real plants with green and red colors, there was a difference in the level of level of relative theta power spectrum (RT) only. This result indicates that plants with green colors are more effective in improving internal concentration than those with red colors. When real plants with natural colors were compared with their artificial colors, the two color stimuli of real plants showed a higher level of RT and relative low beta power spectrum (RLB) that the rest four artificial color stimuli. However, the artificial color stimuli including the photos and color schemes of real plants showed a higher level of relative mid beta power spectrum (RMB), relative high beta power spectrum (RHB) and brain activity (SEF95) and a higher ratio of SMR to theta (RST) and ratio of mid beta to theta (RMT) than the natural color stimuli of real plants. This result can be interpreted that the natural color stimuli of real plants are more effective in increasing stability and relaxation, and that the artificial color stimuli are more effective in increasing attention than the color stimuli of real plants, but cause a high 
level of stress and strain $(p<.05)$. The correlation of the color stimuli of two varieties of a foliage plant with EEG and emotional words was analyzed, and it was found that the groups of 'Angel' plants with red colors showed a statistically significantly higher correlation with EEG than the groups of 'Silver Queen' plants with green colors. In terms of psychological responses to color stimuli of plants, the environments in which 'Silver Queen' plants with green colors were placed tended to be distributed more on the right side of the scale of emotional words such as "comfortable" and "calm" that the environments in which 'Angel' plants with red colors were placed. These results seemed to indicate that the natural colors of real plants can be used in a place where attention is required in a state of stability and relaxation, and that the artificial colors of the photos and color schemes of plants can be used in a place where a high level of concentration is required for a short period of time. Although there were a couple of difficulties in conducting this test among pre-seniors in their 50s or older, including recruiting subjects, it will be necessary to conduct additional studies targeting not only healthy pre-seniors but also those with chronic diseases.

\section{References}

Berger, H. 1929. Über das elektrekephalogram des menschen (On the human electrocephalogram). Arch. Psychiatr. Nervenkr. [Eur. Arch. Psychiatry Neurol. Sci.] 87(1):527-570. https://doi.org/10.1007/BF01797193

Chang, C.Y. and P.K. Chen. 2005. Human response to window views and indoor plants in the workplace. HortScience 40(5):1354-1359. https://doi.org/10.21273/HORTSCI.40.5.1354

Choi, K.O., K.J. Bang, and J. Huh. 1997. A study on the visual image assessment of interior landscaping plants. J. Korean Inst. Landsc. Archit. 25(3):101-110.

Hutchison, M. 1996. Megabrain: New tools and techniques for brain growth and mind expansion (2nd ed.). New York, NY: Ballantine Books.

Im, S.B. 2009. Theories in landscape analysis (Rev. ed.). Seoul, Korea: Seoul National University Press.

Jang, H.S., E.H. Yoo, K.J. Kim, and H.H. Jung. 2015. Preference and image perception for color and shape in green interior. J. Korean Soc. People Plants Environ. 18(5):413-420. https://doi.org/10.11628/ksppe.2015.18.5.413

Jang, H.S., J.Y. Kim, K.S. Kim, and C.H. Pak. 2014. Human brain activity and emotional responses to plant color stimuli. Color Res. Appl. 39(3):307-316.

Jasper, H.H. 1958. The ten-twenty electrode system of the International Federation. Electroencephalogr. Clin. Neurophysiol. 10:371-375.

Jin, B.H. 2011. Electroencephalogram. Seoul, Korea: Korea Medical Book Press.

Jo, K.D. 2009. Development of environment-friendly streetscape design model considering sensibility ergonomics. Master's thesis, Wonkwang University, Iksan, Korea.

Kim, B.K. 1997. Study regarding visual preference anger analysis of an indoor landscape architecture plant. Doctoral dissertation, Kyunghee University, Suwon, Korea.

Kim, D.S. and J.U. Choi. 2001. Electroencephalogram. Seoul, Korea: Korea Medical Book Press.

Kim, E.I. 1998. A study of sight-psychological effects by a color area of green space. J. Korean Inst. Landsc. Archit. 26(1): 36-43.

Kim, J.J. 2009. Visual preference about bench color in urban park. Master's thesis, Korea University, Seoul, Korea.

Kim, J.Y. and H.S. Lee. 2009. A study on interior wall color based on measurement of emotional responses. Korean J. Sci. Emot. Sensib. 12(2):205-214.

Kim, K.M. 2012. Study on the effects of forest healing according to types of recreational forests. Doctoral dissertation, Chungbuk National University, Cheongju, Korea.

Kim, Y.J. 2000. Development of a brain-cycle learning model based on the electroencephalographic analysis of learning activities and its application to science learning. Doctoral dissertation, Seoul National University, Seoul, Korea. 
Korea Neuropsychiatric Association. 1997. Neuropsychiatry. Seoul, South Korea: Hana Medical Books.

Küller, R., B. Mikellides, and J. Janssens. 2009. Color, arousal, and performance - A comparison of three experiments. Color Res. Appl. 34(2):141-152. https://doi.org/10.1002/col.20476

Kwon, Y.G. and J.E. Park. 2004. A study on the effect of green color of residential space based on color therapy. J. Korean Soc. Color Stud. 18(2):1-11.

Lee, J.H. 2009. The influence of forest scenes on psychophysiological responses. Master's thesis, Chungbuk National University, Cheongju, South Korea.

Lee, J.S. and K.C. Son. 1999. Effects of indoor plant and various colors stimuli on the changes of brain activity and emotional responses. J. Korean Soc. Hortic. Sci. 40(6):772-776.

Li, X., Z. Zhang, M. Gu, D.Y. Jiang, J. Wang, Y.M. Lv, Q.X. Zhang, and H.T. Pan. 2012. Effects of plantscape colors on psycho-physiological responses of university students. J. Food Agri. Environ. 10(1):702-708. https://doi.org/10.1234/4.2012.2762

Osgood, C.E., G.J. Suci, and P.H. Tannenbaum. 1957. The measurement of meaning. Champaign, IL: University of llinois Press.

Ottosson, J. and P. Grahn. 2008. The role of natural settings in crisis rehabilitation: How does the level of crisis influence the response to experiences of nature regard to measures of rehabilitation? Landsc. Res. 33(1):51-70. https://doi.org/10.1080/01426390701773813

Park, B.J. 2010. Experimental approach of therapeutic effect of forest recreation activities - Focused on viewing and walking in forest environments -. Doctoral dissertation, Chungnam National University, Daejeon, Korea.

Schacter, D.L. 1977. EEG theta waves and psychological phenomena: A review and analysis. Biol. Psychol. 5(1):47-82.

Shibata, S. and N. Suzuki. 2002. Effect of foliage plant on task performance and mood. J. Environ. Psychol. 22(3):265-272. https://doi.org/10.1006/jevp.2002.0232

Simonov, P.V. 1997. Neurobiological basis of creativity. Neurosci. Behav. Physiol. 27(5):585-591.

Sokolov, E.N. 1963. Higher nervous functions: The orienting reflex. Annu. Rev. Physiol. 25:545-580. https://doi.org/10.1146/annurev.ph.25.030163.002553

Son, K.C., J.S. Lee, and J.E. Song. 1998. Effect of visual recognition of indoor plants on changes of human brain electroencephalography. J. Korean Soc. Hortic. Sci. 39(6):858-862.

Son, K.C., J.S. Lee, and J.E. Song. 1999. Effect of visual recognition of Ficus benjamina and its photograph on changes of human brain electroencephalography and brain blood flow. J. Korean Soc. Hortic. Sci. 40(1):134-138.

Valdez, P. and A. Mehrabian. 1994. Effects of color on emotions. J. Exp. Psychol. Gen. 123(4):394-409.

Wang, K.H. 2008. A study of floral color for adjective images. J. Korean Soc. Color Stud. 22(1):69-80.

Wells, N.M and G.W. Evans. 2003. Nearby nature: A buffer of life stress among rural children. Environ. Behav. 35(3): 311-330. https://doi.org/10.1177/0013916503035003001

Wells, S.E. 1997. Horticultural therapy and the older adult population. Philadelphia, PA: Haworth Press.

Yoo, J.H. 1999. A study on the preferences of interior decoration of apartment houses. Master's thesis, Yeungnam University, Gyeongsan, Korea. 